Published in International Journal of Hydrogen Energy 41 (2016) 21415-21426

Link: http://dx.doi.org/10.1016/j.ijhydene.2016.08.065

Author's post-print Version

\title{
Identification of Critical Parameters for PEMFC Stack Performance Characterization and Control Strategies for Reliable and Comparable Stack Benchmarking
}

Jens Mitzel ${ }^{\mathrm{a},{ }^{*}}$, Erich Gülzow ${ }^{\mathrm{a}}$, Alexander Kabza ${ }^{\mathrm{b}}$, Jürgen Hunger ${ }^{\mathrm{b}}$, Samuel Simon Araya ${ }^{\mathrm{c}}$, Piotr Piela ${ }^{\mathrm{d}}$, Iker Alecha ${ }^{\mathrm{e}}$, Georgios Tsotridis ${ }^{\mathrm{f}}$

${ }^{a}$ German Aerospace Center (DLR), Institute of Engineering Thermodynamics, Pfaffenwaldring 38-40, 70569 Stuttgart, Germany

${ }^{\mathrm{b}}$ Zentrum für Sonnenenergie- und Wasserstoff-Forschung Baden-Württemberg (ZSW), Helmholtzstraße 8, 89081 Ulm, Germany

${ }^{\mathrm{c}}$ Aalborg University, Department of Energy Technology, Pontoppidanstraede 101, DK-9220 Aalborg East, Denmark

${ }^{\mathrm{d}}$ Mościcki Industrial Chemistry Research Institute (ICRI), Rydygiera 8, 01-793 Warsaw, Poland

${ }^{\mathrm{e}}$ IK4-CIDETEC, Parque Científico y Tecnológico de Gipuzkoa, Po Miramón 196, 20009 Donostia-San Sebastián, Spain

${ }^{\mathrm{f}}$ European Commission, Directorate-General Joint Research Centre (JRC), Institute for Energy and Transport, Westerduinweg 3, NL-1755 LE Petten, The Netherlands

* Corresponding author. Phone: +49 711 6862-8063, fax: +49 7116862 747, e-mail: Jens.Mitzel@dlr.de 


\begin{abstract}
This paper is focused on the identification of critical parameters and on the development of reliable methodologies to achieve comparable benchmark results. Possibilities for control sensor positioning and for parameter variation in sensitivity tests are discussed and recommended options for the control strategy are summarized. This ensures result comparability as well as stable test conditions. E.g., the stack temperature fluctuation is minimized to about $1{ }^{\circ} \mathrm{C}$. The experiments demonstrate that reactants pressures differ up to 12 $\mathrm{kPa}$ if pressure control positions are varied, resulting in an average cell voltage deviation of $21 \mathrm{mV}$.

Test parameters simulating different stack applications are summarized. The stack demonstrated comparable average cell voltage of $0.63 \mathrm{~V}$ for stationary and portable conditions. For automotive conditions, the voltage increased to $0.69 \mathrm{~V}$, mainly caused by higher reactants pressures.

A benchmarking concept is introduced using "steady-state" polarization curves. The occurring $20 \mathrm{mV}$ hysteresis effect between the ascending and descending polarization curve can be corrected calculating the mean value of both voltages. This minimizes the influence of preceding load levels, current set points, and dwell times.
\end{abstract}

\title{
Keywords
}

Polymer electrolyte membrane fuel cell; stack benchmarking; critical parameters; parameter control; test operating conditions; "Steady-state" polarization curve 


\section{List of Symbols and Abbreviations}

PEMFC Polymer electrolyte membrane fuel cell

SOFC Solid oxide fuel cell

MCFC Molten carbonate fuel cell

DMFC Direct methanol fuel cell

APU Auxiliary power unit

CHP Combined heat and power

HFR High frequency resistance

TOCs Test operating conditions

OCV Open circuit voltage

$\mathrm{RH}_{\text {fuel }}, \mathrm{RH}_{\mathrm{ox}} \quad$ Relative humidity of fuel and oxidant (defined at stack inlets); \%

$\mathrm{DP}_{\text {fuel }}, \mathrm{DP}_{\text {ox }} \quad$ Dew point temperatures of fuel and oxidant (defined at stack inlets); ${ }^{\circ} \mathrm{C}$

$\lambda_{\text {fuel }}, \lambda_{\text {ox }} \quad$ Stoichiometric ratios of fuel and oxidant (defined at stack inlets);

dimensionless

$\mathrm{p}_{\text {fuel }}, \mathrm{p}_{\mathrm{ox}} \quad$ Absolute pressures of fuel and oxidant (defined at stack outlets); $\mathrm{kPa}_{\mathrm{abs}}$

$\mathrm{p}_{\text {fuel,in }}, \mathrm{p}_{\text {fuel,out }} \quad$ Absolute pressures of fuel at stack inlet and outlet; $\mathrm{kPa} \mathrm{abs}_{\mathrm{abs}}$

$\mathrm{p}_{\text {ox,in }}, \mathrm{p}_{\mathrm{ox}, \text { out }} \quad$ Absolute pressures of oxidant at stack inlet and outlet; $\mathrm{kPa}_{\mathrm{abs}}$

$\mathrm{T}_{\text {cool,in }}, \mathrm{T}_{\text {cool,out }}$ Coolant temperatures at stack inlet and outlet; ${ }^{\circ} \mathrm{C}$

$\mathrm{T}_{\text {stack }}$

Stack temperature (defined by coolant temperature at stack inlet); ${ }^{\circ} \mathrm{C}$

$t_{\text {end }}$

Time until end-of-test; min

$\mathrm{I}_{\text {stack }}$

Stack current; A

$\mathrm{i}_{\text {stack }}$

Stack current density; $\mathrm{A} \mathrm{cm}^{-2}$

$\mathrm{U}_{\text {stack }}$

Stack voltage; V

$\mathrm{U}_{\mathrm{av}, \mathrm{cell}}$

Average cell voltage; $\mathrm{V}$

$\mathrm{U}_{\text {min,cell }}$

Minimum cell voltage; $\mathrm{V}$

$\mathrm{U}_{\text {max,cell }}$

Maximum cell voltage; $\mathrm{V}$

$\mathrm{F}$

Faraday constant; $96485.33 \mathrm{C} \mathrm{mol}^{-1}$

$\mathrm{N}$

Number of single cells in the stack; dimensionless

$\mathrm{V}_{\mathrm{m}}$

Standard $\left(0{ }^{\circ} \mathrm{C}, 101.325 \mathrm{kPa}_{\text {abs }}\right)$ molar volume of ideal gas; $22.414 \mathrm{~L} \mathrm{~mol}^{-1}$

$\mathrm{Q}_{\text {fuel }}, \mathrm{Q}_{\mathrm{ox}} \quad$ Fuel and oxidant flows at stack inlets; $\mathrm{L} \mathrm{min}^{-1}$

$\mathrm{x}_{\mathrm{H} 2}, \mathrm{x}_{\mathrm{O} 2}$

Volumetric ratios of hydrogen in fuel and oxygen in oxidant; dimensionless 


\section{Introduction}

Polymer electrolyte membrane fuel cell (PEMFC) stacks are the main components in fuel cell systems and convert the chemical energy from the fuel to electrical and thermal energy usable for different applications. Compared with other energy converters, PEMFC systems are considered as one of the most effective and promising power systems due to high fuel-toelectricity conversion efficiency and low to zero emission [1]. Nevertheless, several challenges need to be overcome for the commercialization of this technology. At the moment, the required investments for PEMFC stacks and systems are still too high due to the costs of the used components, the manufacturing costs and the complexity of the system [2,3]. Apart from the costs, the main challenges for competitive fuel cell systems are stack performance and durability [4,5]. All these aspects are examined in many laboratories and improvements are ongoing by component [6,7] and stack design modifications [8-10]. The reliability of the stack characterization and of the benchmark results is thereby crucial because many parameters have significant impact on the results and may vary using different test hardware and test procedures. Therefore, the use of standardized procedures and clear definitions of all influential parameter sensors are of high importance to assure reliable and comparable test results for different test objects as well as for different test facilities. Consequently, the harmonization of PEMFC tests at the stack level is important in order to accelerate stack development and to benchmark stacks. The resulting procedures are of high interest for stack manufacturers, system integrators and for academia.

A search for already existing test procedures for PEMFC results in many procedures for the component and single cell level, but only a few procedures are dedicated to the stack level. The available stack procedures are typically limited to a certain application and, consequently, focus on testing specific goals of this application. The methodology of these tests is mainly similar to single cell characterization. However, the procedures have to be defined more precisely to cover the inhomogeneous distribution of parameters within a stack.

An international standard exists for the single cell level, IEC/TS 62282-7-1 [11], including definitions for nomenclature, test hardware, cell assembling, test procedures, and test reporting. The test procedures cover different aspects: (i) constant current and voltage tests, (ii) high frequency resistance (HFR) and mass transport limited current, (iii) current-voltage characteristics using different reactant concentrations and compositions including impurities, (iv) sensitivity tests to reactants stoichiometric ratios, pressures and humidity as well as cell 
temperature, and (v) durability tests using constant load, load cycling and start-stop cycling. A respective standard for the PEMFC stack level has not been defined so far.

The U.S. Drive Fuel Cell Tech Team [12] and the U.S. Department of Energy (DoE) [13] have published quite similar test protocols mainly focused on component characterization for automotive application, but procedures for the measurement of polarization curves and for durability tests using a dynamic load cycle are also given. Polarization and durability tests address the single cell and the stack levels, and the information given in the document is limited to the test operating conditions and the test sequence. A definition of the parameter control strategy is not included in the document and, consequently, reliable stack characterization seems to be challenging using these procedures.

The EU-funded projects FCTESTNET [14] and FCTES ${ }^{\mathrm{QA}}$ [15] have developed test procedures for single cells, stacks and systems for different applications and different types of fuel cells. These procedures cover the field of PEMFC, SOFC and MCFC. The procedures defined for the PEMFC stack level deal with sensitivity tests for reactant pressure and stoichiometry, polarization curve measurements, and durability test using constant load and dynamic load cycling. Positions of the control sensors and control strategies are partially defined in the available documents and are included in the discussion of these aspects in the present paper.

Besides the mentioned procedure definitions, two industrial standards are available for PEMFC stack performance characterization, a Japanese Industrial Standard (JIS) and a standard by the Society of Automotive Engineers (SAE). The JIS C 8832 standard [16] describes performance test procedures for the characterization of stationary PEMFC stacks. Procedures for current-voltage curves and tests of sensitivity regarding stack temperature, reactant utilization, and reactant humidity are given. Due to the focus on stationary applications including the use of reformate fuel, the impact of impurities is one of the main objectives of this standard. Thereby, the effects of carbon monoxide and ammonia concentration in the fuel, as well as the effect of nitrogen dioxide, sulfur dioxide, ammonia, and toluene concentration in the oxidant are covered.

The SAE J2617 standard summarizes test procedures for performance tests of PEMFC stacks for automotive application [17]. These procedures cover: (i) open circuit voltage (OCV) tests, (ii) polarization curves using different reactant concentrations, (iii) sensitivity sweeps for reactants stoichiometric ratios, humidity, and pressures as well as coolant temperature and flow rate, and (iv) voltage response tests in constant load and dynamic load cycling. 
The characterization of PEMFC stacks has to consider existing parameter gradients across the stack, like stack temperature and reactant pressure. This requires identification of critical parameters with high impact on the test results as well as clear definitions of the positions of all parameter control sensors and of the required parameter control strategies. These definitions are not consistent or not included in the above listed procedures and standards. The EU-funded project Stack-Test was initiated by the European fuel cell OEMs to create universal standards for operating conditions and test reference procedures to assure reliable benchmarking of different stacks. The benchmark results can be used to identify the best stack design for a certain application. This paper summarizes the achievements of the project and points out the requirements for reliable and comparable stack performance characterization and benchmarking. The prepared test procedures, covering not only performance, but also durability and safety aspects, can be obtained at the project website [18]. Within the presented work, the possibilities for the positioning of the parameter control sensors and for the variation of parameters in sensitivity tests are discussed in detail and recommendations for the resulting control strategy are given based on these discussions. Test operating conditions (TOCs) for benchmark tests for different applications are also summarized to enable the comparison of research achievements, even if these conditions do not totally match the conditions in the target system. Furthermore, a concept to obtain a "steady-state" polarization curve without actual steady-state measurements is introduced. The achievements presented in this paper thereby remove an existing lack of definitions needed for reliable and comparable PEMFC stack performance characterization. Consequently, the developed benchmark methodology can be a powerful tool for system integrators to identify the best stack for a certain application, for stack manufacturers for quality assurance and stack development, and for academia to assure reliable comparison of research results.

\section{Experimental}

A liquid-cooled PEMFC stack manufactured by ZSW (Zentrum für Sonnenenergie- und Wasserstoff-Forschung Baden-Württemberg) was used for the tests presented in this work. This stack contained graphitic composite bipolar plates with 10 cells and an active electrode area of $96 \mathrm{~cm}^{2}$. It represents a typical stationary stack with nominal electrical power output of $480 \mathrm{~W}$. 
All tests were carried out using an in-house manufactured $1 \mathrm{~kW}$ test station using hydrogen (grade 5.0 by Linde AG) and compressed ambient air (particle-filtered, dried and oil-free) for reactants. The used test station is equipped with direct evaporators (CONTROLLED EVAPORATOR MIXER) and high precision liquid mass flow controllers (mini CORIFLOW) by Bronkhorst HIGH-TECH BV for reactant humidification. The reactant flow is adjusted by gas mass flow controllers (red-y smart series by Vögtlin Instruments AG) and the reactant pressure by pressure controllers (EL-PRESS by Bronkhorst). Furthermore, a ZS Electronic Load (Höcherl \& Hackl GmbH) is used for stack current control and the stack temperature is adjusted using an Integral XT $8 \mathrm{HW}$ thermostat (Lauda Dr. R. Wobser GmbH \& Co. KG). Deionized water is used for coolant. All stack reactant supply pipes are electrically heated and thermally insulated to avoid water condensation in the feed streams.

\section{Sensor Definition for Parameter Control}

The stack is frequently considered as a black box with inlet and outlet ports for benchmark tests. Consequently, the aim of these tests is not to internally diagnose what is happening inside the stack, but to reliably measure its performance under certain prefixed conditions. While the available test procedures mainly define the methodology and the parameter set points for this purpose, the positions of the used sensors for controlling these parameters are usually not defined. Certainly, the placement of the control sensor has a high impact on the test results and has to be defined to achieve a comparable and reliable control strategy for stack benchmarking. Otherwise a significant variation of the test results can occur caused by the test equipment and not by the tested stack. Therefore, this section will summarize and discuss the influence of the sensor positions for the different parameters controlled during PEMFC stack testing. In general, aspects regarding general safety, stack safety, parameter stability, test duration, and comparability to an operating fuel cell system have to be considered for the definition of each sensor position.

\subsection{Control of stack temperature:}

An operating PEMFC stack is not isothermal due to the considerable thermal power being generated inside of it and the thermal conductivities of its components not being infinite. The temperature of the stack should be thought of only as an average of (as many as possible) 
temperatures prevailing at different, evenly spread locations across the stack volume. This ideal stack temperature can neither be measured nor controlled in practice. For control purposes, a location needs to be defined, where the temperature could reflect the ideal stack temperature to some extent. There are many possibilities to measure and define the stack temperature during PEMFC testing. The most common positions for the stack temperature control sensor are the coolant inlet and the coolant outlet close to the stack, but also temperature measurements in the reactant outlets can be found in the literature [19-21]. The controlled stack temperature can be strongly influenced by the stack design, if the last option is used. The stack can use a co-flow or a counter-flow configuration between the reactants and the coolant. Depending on this configuration, the temperatures measured in the reactant outlets can be related to the coolant inlet temperature or the coolant outlet temperature. To avoid this influence of the stack design, the temperature control sensor is commonly placed in the coolant. The control sensor position is not defined consistently in the existing procedures. SAE [17] and FCTESTNET [14] use the coolant inlet temperature and FCTES ${ }^{\mathrm{QA}}$ [15] the coolant outlet temperature for the definition of the stack temperature. The other existing procedures by JIS [16], U.S. Drive [12], DoE [13], and IEC [11] do not clearly define the position of this control sensor. Consequently, a closer look on the influence of this position is needed.

Electrode flooding resulting in partial reactant starvation is known to be an important stressor regarding stack lifetime and has a high impact on the stack performance. Consequently, the risk of flooding should be minimized during test procedures. The highest risk is associated with highly humidified reactants and with high amount of produced water at high electrical load. The hypothetical example given in Figure 1 should be used to discuss this aspect. Therein, the stack temperature is specified to $65{ }^{\circ} \mathrm{C}$, the reactants are fully saturated $(100 \%$ $\mathrm{RH}$ at the stack temperature set point or a dew point of $65^{\circ} \mathrm{C}$ ), and the stack thermal power dissipation requires a temperature difference of $5{ }^{\circ} \mathrm{C}$ between the stack coolant inlet and the stack coolant outlet at the given coolant flow rate.

If the stack temperature is controlled according to the coolant temperature at the stack inlet (Figure 1a), the resulting temperature of the coolant at stack inlet is $65{ }^{\circ} \mathrm{C}$ and the temperature near to the stack outlet is $70{ }^{\circ} \mathrm{C}$ due to the produced heat inside the stack. The stack temperature is not below the reactants dew points and consequently the risk of water condensation caused by the saturated reactants at the reactant inlets is minimized. Additionally, the removal of the produced water in the stack is facilitated due to the increasing temperature across the stack. 
On the contrary, if the stack temperature is controlled according to the coolant temperature at the stack outlet (Figure $1 \mathrm{~b}$ ), the resulting temperature is $60{ }^{\circ} \mathrm{C}$ at the stack inlet and $65^{\circ} \mathrm{C}$ at the stack outlet, respectively. Consequently, the stack temperature near the reactant inlets can be $5{ }^{\circ} \mathrm{C}$ lower than the dew point of the fully saturated reactants (for this hypothetical example), resulting in a risk of water condensation at the stack reactants inlets, if the reactant inlets are located near the cooling inlet. The capability to remove water from the stack is additionally reduced due to the lower temperatures inside the stack compared to the option presented in Figure 1a.

It is obvious that the risk of water condensation and electrode flooding can be reduced using the coolant inlet temperature for the definition of the stack temperature during testing.

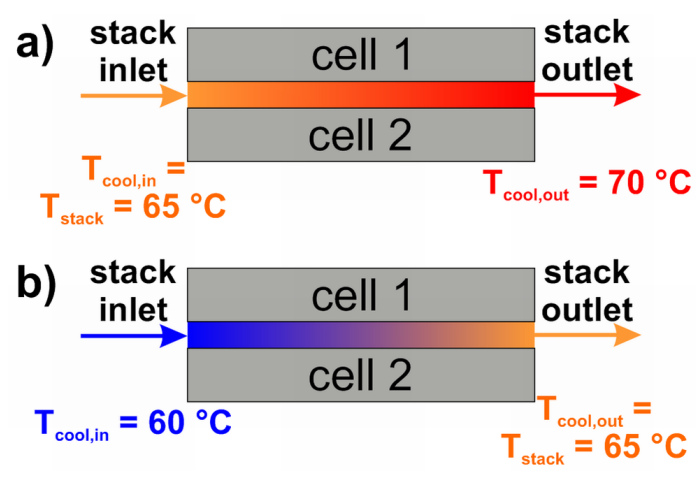

Fig. 1. Example of the temperature profile in a PEMFC stack using the coolant temperature at stack inlet (a) and at stack outlet (b) for stack temperature control.

It is also important to assure the stability of the parameters for reliable stack benchmarking. Figure 2 demonstrates the stability of the stack temperature during load variation when the stack temperature was either controlled at the coolant inlet or at the coolant outlet. The stability was generally lower and temperature variations up to $3{ }^{\circ} \mathrm{C}$ could be detected when the temperature was controlled at the outlet (Figure 2a). In contrast, the control sensor position at the coolant inlet resulted in temperature variations of only $1{ }^{\circ} \mathrm{C}$ (Figure $2 \mathrm{~b}$ ). The faster and more accurate temperature control using the temperature sensor in the coolant at stack inlet seems to be a result of the non-varying thermal load between the used thermostat and this sensor. Thereby, the fluctuation of the stack temperature and the condensation of water can be minimized. This results in a higher stability of the stack voltage used as the test output parameter for stack performance validation. The higher stability can result in shortened test duration because the time for temperature stabilization can be decreased for each test step. In the given example, the test duration could be reduced by 10 minutes. 

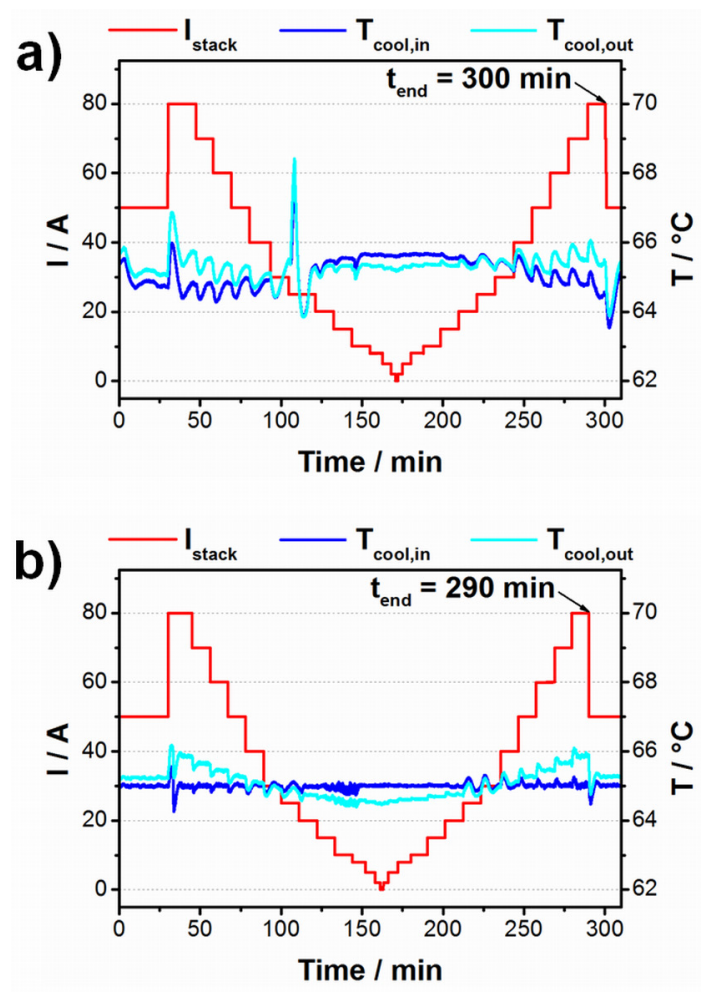

Fig. 2. Temperature stability during load variation when the stack temperature is controlled at the coolant outlet (a) and at the coolant inlet (b). TOCs: $\mathrm{T}_{\text {stack }}=65^{\circ} \mathrm{C} ; \lambda_{\text {fuel }}=1.43 ; \lambda_{\text {ox }}=2.5 ; \mathrm{DP}_{\text {fuel }}=\mathrm{DP}_{\text {ox }}=61.5^{\circ} \mathrm{C} ; \mathrm{p}_{\text {fuel }}=\mathrm{p}_{\text {ox }}=$ $150 \mathrm{kPa}_{\mathrm{abs}}$.

Finally, the comparability of the test results with the later application has to be taken into account. The stack temperature as well as the required cooling power in a PEMFC system is controlled according to the temperature at the outlet of the used cooler upstream from the stack. Consequently, the stack temperature controlled at the coolant inlet results in operating conditions closer to the system application.

Considering all these aspects, it is highly recommended to use a temperature sensor in the coolant near the stack inlet for the definition and the control of the stack temperature to assure reliable and comparable characterization and benchmark results.

\subsection{Control of reactant pressure}

In general, it is recommended to use four pressure sensors for reliable reactants pressures control and for surveillance of the differential pressure between the electrode sides. One should be placed near the stack inlet and one near the stack outlet in both reactant lines. The reactants pressures in each compartment can be controlled with respect to either of the sensors and the used sensor position has a high impact on the test results as can be seen in the 
polarization curve measurements presented in Figure 3. The used stack, the set points for the reactant pressures and the electrical load as well as the dwell times and analysis times during the test points were identical for both presented measurements, but the used control sensor was varied.

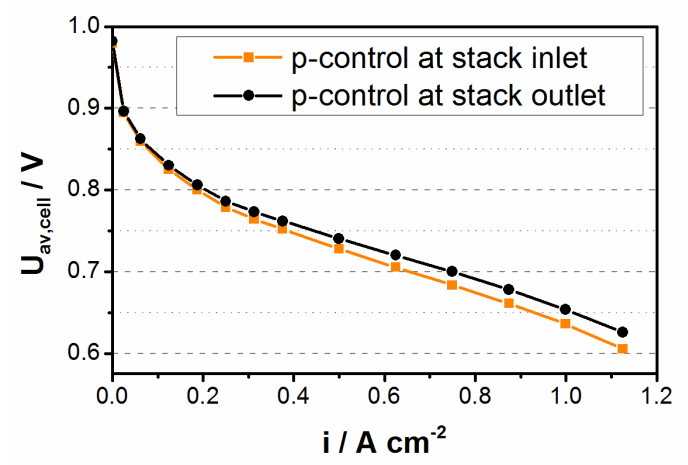

Fig. 3. Polarization curve results using different sensor positions for the reactants pressures control. TOCs: $T_{\text {stack }}$

$$
=80^{\circ} \mathrm{C} ; \lambda_{\text {fuel }}=1.5 ; \lambda_{\text {ox }}=2.0 ; \mathrm{DP}_{\text {fuel }}=\mathrm{DP}_{\text {ox }}=63.5^{\circ} \mathrm{C} ; \mathrm{p}_{\text {fuel }}=\mathrm{p}_{\text {ox }}=150 \mathrm{kPa}_{\mathrm{abs}} .
$$

It is obvious that the deviation of the test results was caused by the reactant pressures in the examined stack. The differences in the reactant pressures during both measurements are presented in Figure 4 and are directly linked to the pressure drop in the reactants conduits across the stack and the used sensor position. If the reactant pressure was controlled at the stack outlet (Figure $4 \mathrm{a}$ ), the corresponding pressures at the stack inlet were higher than the defined set points. In accordance, the reactant outlet pressures were lower than these set points when the pressure was controlled at the stack inlet (Figure 4b). The occurring pressure difference between the inlet and the outlet depends on the reactant flow and the flow fields in the examined test object. The deviation of the test results furthermore depends on the stack sensitivity to pressure variation. In the presented test, the air pressure was up to $12 \mathrm{kPa}$ higher and the hydrogen pressure up to $4 \mathrm{kPa}$ higher when the reactant outlet sensor was used for pressure control. As a consequence, the average cell voltage was up to $21 \mathrm{mV}$ higher and the performance gap increased with increasing load level due to the higher reactant flow. This significant deviation of the test results has demonstrated the need of a uniform definition of the pressure control sensor position for comparable tests. Otherwise, the test results from different testing facilities could be misinterpreted. 

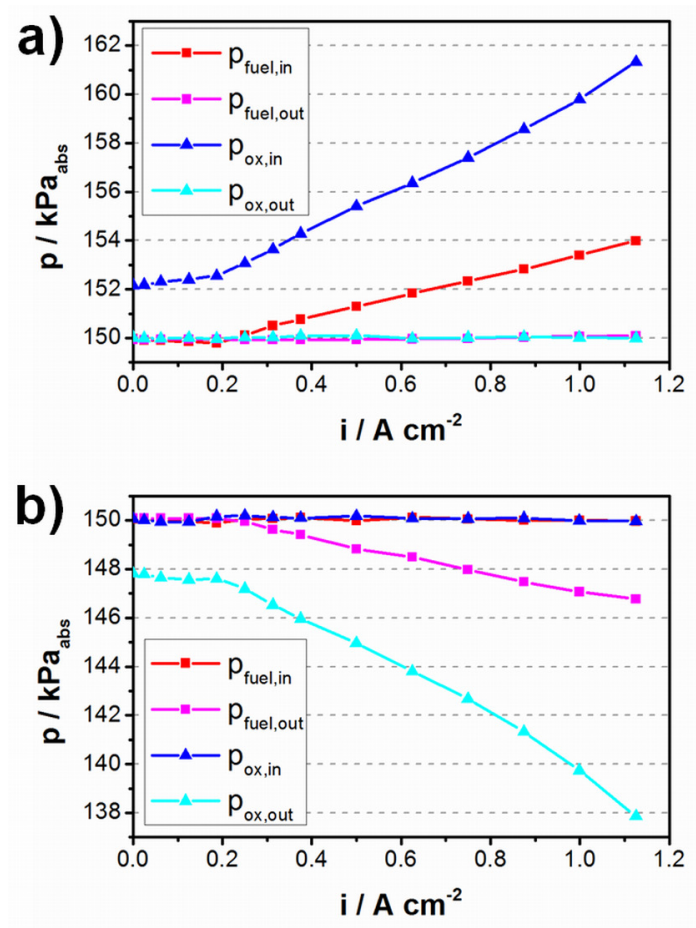

Fig. 4. Pressure behavior during the polarization curve measurements presented in Figure 3 when the reactant pressure is controlled at the stack outlet (a) and at the stack inlet (b).

Certainly, this sensor position is not defined uniformly in existing test procedures and standards. JIS [16] and SAE [17] refer the stack operating pressure to the stack inlet while U.S. Drive [12], DoE [13], and FCTES ${ }^{\mathrm{QA}}$ [15] refer this pressure to the stack outlet. IEC [11] and FCTESTNET [14] have not defined the control sensor position directly, but the selected option has to be stated in the test report. Different aspects should be considered for the decision of which sensor position is more meaningful for the reactant pressure control, especially for the PEMFC stack level:

- The reactant pressure in fuel cell systems is controlled by the use of an electronic throttle valve placed downstream from the stack. Consequently, test station results using reactant pressure control at the stack outlet are comparable to the subsequent application.

- The pressure after the air compressor or blower can be a specific parameter for the operating conditions in a certain system. Hence, the pressure control at the stack inlet can be beneficial for stack benchmarking by system integrators.

- Control sensors positioned at the stack outlet are favorable for the definition of test set points, especially for low pressure tests. E.g., if tests should be realized at atmospheric pressure, this set point is clearly referred to the stack outlet without the use of back pressure. Additionally, low pressure set points could not be realized using the stack 
inlet for control position when the difference of these set points from the atmospheric pressure is lower than the pressure drop across the stack. In such case, the reactant pressure at the stack outlet would have to be reduced below ambient. This is not applicable, neither for the characterization in test stations, nor for the use in systems.

- The pressure control in a test station can be realized easier and faster using a control sensor on the same side of the stack where the pressure controller is placed. This aspect is especially of interest for dynamic load cycling including load changes directly linked to reactant flow changes and pressure drop changes. Thereby, the pressure controller only needs to react to the flow variation when the control sensor is positioned at the stack outlet. On the contrary, the controller needs to react additionally to the varied pressure drop when the control sensor is positioned at the stack inlet.

- Using the control sensor at the stack inlet is favorable regarding stack safety. In this case the reactant outlet pressure is always lower than the defined pressure. Therefore, the maximum differential anode-to-cathode pressure cannot be exceeded as long as the pressure set points are defined within the specifications of the stack manufacturer. In contrast, the higher pressure drop on the cathode side can cause a too high differential pressure when the control sensors are placed at the reactant outlets, even when the set points are within this specification.

The choice of the sensor position for pressure control requires weighting all these aspects because different aspects are favorable for different options. It seems favorable to control the pressure at the reactant outlet and surveil the maximum differential pressure as well as the pressure drops in the stack compartments carefully. If needed for benchmark tests by system integrators, the outlet pressure set point can be adapted to the inlet pressure. Hence, the test operating conditions are as close as possible to the application environment while the safety aspects are covered additionally. All harmonized procedures prepared by the Stack-Test project use pressure sensors in the reactant outlets for pressure control. Furthermore, the use of $\mathrm{kPa}_{\mathrm{abs}}$ is recommended for the pressure unit in accordance with the recommendations by ISO [11]. 


\subsection{Control of reactant humidity}

The control position of the reactant humidity is consistently defined in the existing test procedures and standards by all organizations [11-17]. The humidity of the reactants is defined and controlled at the stack inlet, the only meaningful position for this parameter. Nevertheless, the definition of the humidity is possible using the relative humidity or the dew point temperature of the reactants. The relative humidity is more common in existing procedures and in the literature, but the use of dew point temperatures assures consistent humidification independent from the humidification system. Furthermore, it can be misleading to use the relative humidity of the reactants. Typically, the gas reactant inlet temperature is slightly higher than the stack temperature to avoid water condensation in the reactant feeds, but the used relative humidity values for PEMFC stack tests are referred to the stack temperature. Consequently, the relative humidity is slightly lower when it is referred to the actual gas inlet temperature. A misinterpretation can have a significant impact on the test results due to the high effect of the humidity level on the stack performance. This misinterpretation can be avoided by the use of dew point temperatures. The dew point temperature of the reactants only depends on the water amount in the feeds and not on an additional parameter, like the gas temperature. Consequently, this humidity parameter can be controlled more precisely due to the absence of the additional influence of gas or stack temperature fluctuation.

In general, a closer look on the used humidification systems is required. The regular calibration of these systems is strongly recommended to assure the correctness of the humidification levels and to identify the dynamic behavior of the humidifiers for various reactant flows. Additionally, on-line detection of the gas inlet humidity can be advantageous, but can only be realized by optical humidity sensors due to the limited resistiveness of other sensors. When bubbler systems or contact humidifiers are used, the temperature of the water phase may be adapted to assure the correct reactant inlet humidity and a sufficient contact area between water and gas phase has to be provided to assure fast establishment of equilibrium between the phases. The latter is especially critical at high gas flow rates. When direct humidifiers (e.g., vaporizers) are used, the amount of vaporized water has to be calculated to attain the correct humidity level. It should be mentioned that the defined sensor position for reactant pressure control at the stack outlet requires online calculation of this amount of water. As mentioned, the humidity level is defined at the stack inlet and the pressure at the stack outlet. The reactant pressure at the stack inlet is a function of the pressure 
drop across the stack and varies during measurements depending on the stack load, the reactant flow, the stack temperature, and the humidity level. The required amount of water for a specified humidity level at the stack inlet is related to the pressure at the stack inlet [21] and therefore it has to be adapted to variations in this pressure during the measurement. This enables comparable measurements between test stations using bubblers and direct humidification systems.

\subsection{Control of stack current and reactant stoichiometry}

The electrical current applied to the stack is controlled by the electrical load connected to the current collectors. This device is typically used for parameter control and as a measurement sensor for the stack current and the stack voltage.

The stoichiometric ratios for the fuel and the oxidant have to be transformed to the related reactant flow based on Equation 1 for hydrogen and on Equation 2 for air.

$$
\begin{aligned}
& Q_{\text {fuel }}=\frac{\mathrm{N} \cdot \mathrm{V}_{\mathrm{m}} \cdot \mathrm{I}_{\text {stack }} \cdot \lambda_{\text {fuel }}}{2 \cdot \mathrm{F} \cdot \mathrm{x}_{\mathrm{H} 2}} \\
& \mathrm{Q}_{\mathrm{ox}}=\frac{\mathrm{N} \cdot \mathrm{V}_{\mathrm{m}} \cdot \mathrm{I}_{\text {stack }} \cdot \lambda_{\mathrm{ox}}}{4 \cdot \mathrm{F} \cdot \mathrm{x}_{\mathrm{O} 2}}
\end{aligned}
$$

The reactant flows are controlled and measured by the use of mass flow controllers placed upstream from the stack. Consequently, the stoichiometric values are controlled at the stack inlet. The positions for stack current and stoichiometry control are consistent in all test procedures available. The recommended sensor positions for the control of all test operating parameters are summarized in Table 1.

\section{Control Strategies for Sensitivity Tests using Variable Parameter Set Points}

Not only the sensor position for parameter control has a high impact on benchmark results, also the direction of parameter changes can influence the test results. This influence is 
obvious for the most common tool for PEMFC stack characterization, the measurement of the stack performance as a function of the stack current or current density in the form of a twoway polarization curve. It is well known that the results from polarization curves determined by current increase (ascending part) and by current decrease (descending part) differ. The resulting hysteresis effect between the two parts of the polarization curve is mainly caused by different humidification levels of the membrane and the presence or the absence of oxide surface species on the catalyst.

Furthermore, additional aspects should be considered for each parameter. Due to the applied parameter variation, the conditions in the stack can vary and stack safety risks should always be minimized. Additionally, the test duration can be affected by the choice of the direction for parameter changes.

The importance of these aspects and the choice for the given recommendations will be discussed in the following. The recommended and the critical directions for parameter changes as well as recommendations for the control sensor positions and for the parameter units are presented in Table 1, summarizing the control strategy for reliable stack benchmarking. In general, it is strongly recommended to realize test procedures under variation of different parameters from the most stable to the most critical conditions.

Table 1: Recommendations for the variation, the control sensor positions, and the units of test operating parameters

\begin{tabular}{ccccc}
\hline Parameter & $\begin{array}{c}\text { Recommended } \\
\text { variation }\end{array}$ & $\begin{array}{c}\text { Critical } \\
\text { variation }\end{array}$ & $\begin{array}{c}\text { Control } \\
\text { sensor }\end{array}$ & Unit \\
\hline $\mathrm{T}_{\text {stack }}$ & low to high & high to low & reactant inlet & ${ }^{\circ} \mathrm{C}$ \\
$\mathrm{DP}_{\text {fuel }}, \mathrm{DP}_{\text {ox }}$ & coolant inlet & ${ }^{\circ} \mathrm{C}$ \\
$\mathrm{I}_{\text {stack }}$ & high to low & low to high & reactant outlet & $\mathrm{kPa}_{\mathrm{abs}}$ \\
\hline $\mathrm{p}_{\text {fuel }}, \mathrm{p}_{\mathrm{ox}}$ & & & reactant inlet & - \\
$\lambda_{\text {fuel }}, \lambda_{\mathrm{ox}}$ & & & & $\mathrm{A}$ \\
\hline
\end{tabular}

\subsection{Variation of reactant humidity}

In general, the reactant humidity, especially the humidity of the oxidant, has a high impact on the humidity state of the membrane and the stack performance. Consequently, the reactant 
humidity level applied to the stack significantly influences the performance of a subsequent test point after variation of the reactant humidity. The most stable operating conditions regarding stack performance can be attained using low humidified reactants while highly humidified reactants can, primarily during high load levels, result in electrode flooding and cell voltage fluctuation caused by the presence of liquid water in the electrodes.

Additionally, the required time for parameter stabilization can be reduced using this direction. When bubbler systems are used for humidification, the heating dynamics of these devices is normally faster than the cooling dynamics. This behavior can result in a decrease of the overall test duration. Considering all these aspects, it is recommended to vary the reactant humidity from low to high dew point temperatures.

\subsection{Variation of stack temperature}

The methodology for the variation of the stack temperature is strongly linked to the variation of the reactant humidity (see section 4.1 ) because the relative humidity of the reactants has to be constant for the evaluation of the impact of the stack temperature. Consequently, the reactant dew points have to be varied according to the stack temperature. In accordance with the methodology for the variation of the reactant humidity, the stack temperature should be increased during a test procedure to minimize the test duration. Thereby, the occurrence of electrode flooding has to be avoided by stack temperature increase prior to dew point increase. Additionally, low stack temperatures in combination with highly humidified reactants can promote water condensation and should be handled with care.

\subsection{Variation of reactant pressure}

It is strongly recommended to vary the reactant pressures from high to low values, if possible. The reactant pressure in test stations is controlled by the use of pressure controllers equipped with valves. The valve opening is adjusted by the controller according to the applied set value. If the reactant pressure increases during a test procedure, the valve opening is reduced until the new pressure set point is reached. This adjustment results in a temporary reduction of the reactant flow in the stack and can cause problems regarding reactant starvation and water accumulation. In contrast, the valve opening is increased temporarily when the reactant 
pressure is decreased. The resulting higher reactant flow avoids critical stack operation during pressure adjustment and is favorable regarding stack safety.

Furthermore, the ordering of pressure set points in descending direction can reduce the test duration, especially for low reactant flow, high gas volumes in the reactant lines of the test station, and high set point differences. The adjustment can be realized faster by the used pressure controller by releasing the required amount of reactants compared to increasing the pressure by letting in additional reactant to the reactant lines.

An example of a test procedure to determine the stack sensitivity to the reactant pressures is given in Figure 5. Both reactant pressures and the electrical load applied to the stack were varied and their impact on the stack voltage was determined. The other test parameters were kept constant. The test profile, the temporal changes of the test parameters, is presented in Figure 5a. As recommended, the reactant pressures were reduced during the test, but pressure increases could not be totally avoided, in order to realize all test points. The pressure increases were minimized for the cathode side to reduce the risk of cathode flooding. Furthermore, these phases were realized carefully to assure sufficient reactant flow across the stack. The test results are shown in Figure 5b. As expected, the stack performance decreased with decreasing reactant pressures. Thereby, the air pressure had a higher impact on the stack voltage, but also the hydrogen pressure influenced the stack performance.
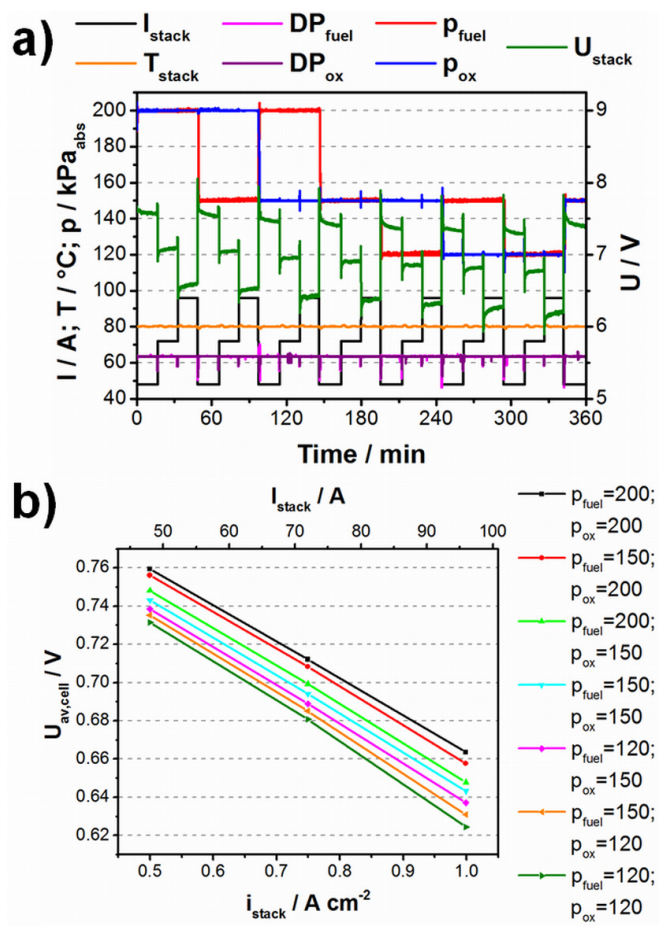

Fig. 5. Test profile (a) and test results (b) for a stack sensitivity test to reactant pressures (in $\mathrm{kPa} a$ abs). TOCs: $\mathrm{T}_{\text {stack }}$

$$
=80^{\circ} \mathrm{C} ; \lambda_{\text {fuel }}=1.5 ; \lambda_{\text {ox }}=2.0 ; \mathrm{DP}_{\text {fuel }}=\mathrm{DP}_{\text {ox }}=63.5^{\circ} \mathrm{C} \text {. }
$$


Following all recommendations given in this paper, a reliable comparison of test results obtained in different testing facilities and using different test equipment is allowed, e.g., for benchmark tests. This aspect was demonstrated by a test series realized in 5 different test facilities across Europe. The test equipment used by the individual facilities varied in terms of the control devices, the test station size, and the humidification system. Furthermore, the number of cells in the examined stacks varied between 10 and 16 cells, while the stack design was the same (ZSW, see section 2). A summary of the test results is presented in Figure 6, representing the stack performance at $200 \mathrm{kPa}_{\mathrm{abs}}$ at different load levels between 0.25 and $1.00 \mathrm{~A} \mathrm{~cm}^{-2}$. Lower electrical load was not applied to the stack to avoid increased electrode degradation caused by high cathodic potentials. The determined performance during the different tests was highly comparable and this demonstrates the reliability of the test results when the test procedure, the used control sensors, and the variation of the parameters were clearly defined, even when the test equipment is different. Nevertheless, some of the examined stacks showed significantly lower performance in some single cells at low electrical load. This behavior seems to have been caused by inhomogeneous reactant distribution, but had no significant impact on the overall test results. The performance of the individual cells can be assessed from the used error bars, representing the deviation between the average cell voltage and the minimum and the maximum single cell voltage ever recorded during the entire analysis time of a test point.

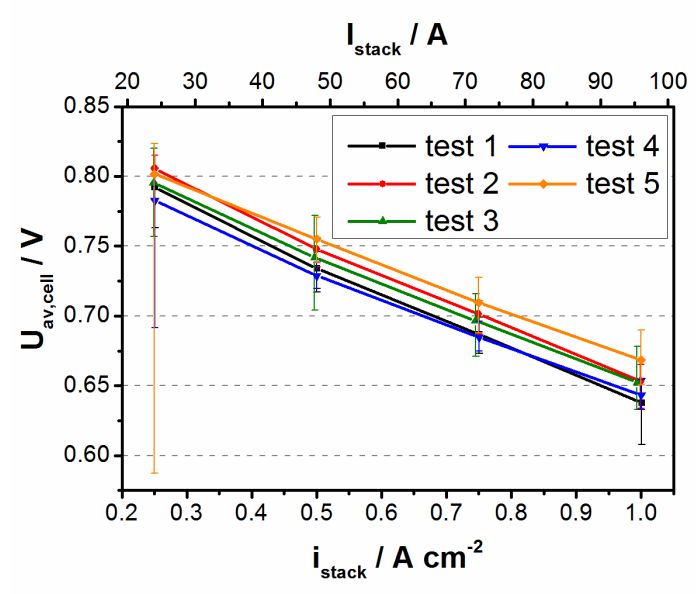

Fig. 6. Summary of test results at different testing facilities. TOCs: $\mathrm{T}_{\text {stack }}=80^{\circ} \mathrm{C} ; \lambda_{\text {fuel }}=1.5 ; \lambda_{\text {ox }}=2.0 ; \mathrm{DP}_{\text {fuel }}=$

$$
\mathrm{DP}_{\text {ox }}=63.5^{\circ} \mathrm{C} ; \mathrm{p}_{\text {fuel }}=\mathrm{p}_{\text {ox }}=200 \mathrm{kPa}_{\mathrm{abs}} \text {. }
$$




\subsection{Variation of stack current}

In general, the single cell voltages in a stack decrease with increasing electrical load and the minimum value is specified by the stack manufacturer to avoid cell damage. Therefore, it is advantageous to realize test procedures using test points with increasing electrical load, especially for fully automated procedures. In this order, the single cell voltages decrease stepwise and the test points can be realized up to a load level, at which a defined minimum cell voltage is reached.

Furthermore, it is important to avoid reactant starvation when the stack current is varied. The reactant flows have to be increased prior to the electrical load increase, and the electrical load has to be decreased prior to the reactant flow decreases. Thereby, the test station dynamics have to be taken into account, especially at low stoichiometric ratios and high gas line volumes.

\subsection{Variation of reactant stoichiometry}

Following the recommendation to realize test procedures from the most stable to the most critical conditions, the variation of the reactant stoichiometric ratios should start at the highest value and should be reduced stepwise. Test points using high reactant stoichiometry are associated with high reactant flow and the produced water can easily be removed from the stack. On the contrary, low stoichiometric ratio and low reactant flow can result in water accumulation in the single cells and invoke electrode flooding. This can result in increased voltage fluctuation. Furthermore, the pressure drop in the gas compartments of the stack is decreased at low stoichiometry and an inhomogeneous reactant distribution between the individual cells may be caused. The resulting local reactant starvation as well as the local electrode flooding can result in cell damage.

\section{Set of Test Operating Conditions for Different Applications}

Even if the TOCs for specific tests by system integrators depend on the target system, harmonized TOCs are important to identify the capability of a stack design (including flow field design and components) for a certain application. Additionally, the performance test results for PEMFC stacks presented in scientific literature cannot be compared because the 
tests were realized using different conditions. Harmonized TOCs can allow the reliable result comparison from different facilities using different stacks to evaluate the achievements from different research activities. Certainly, these TOCs represent a set of parameters simulating the operation in a system and consequently they differ for different applications. A set of representative TOCs for different applications were prepared and summarized in the StackTest project. These TOCs are the result of discussions with companies and research institutions from Europe, Asia and America in several workshops and conferences. The agreed TOCs are based on the state-of-the-art $\mathrm{H}_{2}$-PEMFC and DMFC technologies for the different applications as of the year 2015 and the summary is shown in Table 2. It should be mentioned that two sets of test operating parameters are given for the stack application in automotive propulsion due to two different available approaches. The TOCs marked as "Propulsion 1" are the result of a bottom-up approach (harmonized conditions for single cell tests transferred to stack test conditions) based on the harmonization efforts by the European Commission [22]. The TOCs marked as "Propulsion 2" are the result of a top-down approach (requirements of an automotive fuel cell system transferred to stack tests conditions) achieved in the European project Autostack-CORE [23].

The TOCs simulating the automotive propulsion system are characterized by high pressure, low stoichiometry, and low humidity of the reactants to achieve the power density targets for the stack and the system. The low reactant humidity avoids electrode flooding issues as well as temporal and local reactant starvation by inhomogeneous reactant flow distribution at low stoichiometry [24]. The TOCs for automotive range extenders and automotive auxiliary power units (APUs) differ from the TOCs for propulsion systems because the power output of these systems is significantly lower. Consequently, the available space is of lower importance and the stack can operate at lower pressure, higher stoichiometry and higher humidity of the reactants [25].

Similar conditions can be applied to stationary stacks for combined heat and power application (CHP) except the use of a lower hydrogen stoichiometry. This parameter simulates that CHP systems use natural gas as hydrogen source and a reformer to generate hydrogen. The excess hydrogen is typically only partially recirculated and additionally used for the heating of the reformer and of the desulfurization unit [26]. The low humidity level in tests for backup power application covers the possibility to use oxygen enriched air as oxidant. Due to the lower gas flow at the cathode, the water removal capability at the cathode is decreased and lower humidity reduces the risk of electrode flooding [27]. 
Portable generator systems are commonly air cooled systems with a power output of a few hundred watts. The air is used at ambient pressure (only slightly compressed to overcome the cathodic pressure drop). The TOCs to simulate the hydrogen powered generators are characterized by low temperature due to the low power output [28]. Dry air is used as oxidant to avoid water accumulation problems at the low operating temperature. The DMFC application is represented by higher temperature due to more challenging kinetics. The used fuel is an aqueous solution of methanol requiring a higher fuel stoichiometry due to the slower mass transport in solution [29]. Air humidification is not needed in such systems because the membrane humidity is assured by the presence of liquid water at the anode.

Table 2: Recommended test operating conditions for different applications.

\begin{tabular}{|c|c|c|c|c|c|c|c|c|c|c|}
\hline Application & $\begin{array}{l}\mathbf{T}_{\text {stack }} \\
/{ }^{\circ} \mathbf{C}\end{array}$ & $\begin{array}{c}\mathbf{T}_{\text {gas,in }} \\
/{ }^{\circ} \mathbf{C}\end{array}$ & $\begin{array}{c}\lambda_{\text {fuel }} \\
/-\end{array}$ & $\begin{array}{c}\lambda_{\text {ox }} \\
/-\end{array}$ & $\begin{array}{c}\mathbf{R H}_{\text {fuel }} \\
/ \% \\
\end{array}$ & $\begin{array}{l}\mathbf{D P}_{\text {fuel }} \\
/^{\circ} \mathbf{C} \\
\end{array}$ & $\begin{array}{c}\mathbf{R H}_{\mathbf{o x}} \\
/ \% \\
\end{array}$ & $\begin{array}{l}\mathbf{D P}_{\mathbf{o x}} \\
/^{\circ} \mathbf{C}\end{array}$ & $\begin{array}{c}\mathbf{p}_{\text {fuel }} \\
/ \mathbf{k P a}_{\mathbf{a b s}}\end{array}$ & $\begin{array}{c}\mathbf{p}_{\mathbf{o x}} \\
/ \mathbf{k P a} \mathbf{a}_{\mathbf{a b s}}\end{array}$ \\
\hline $\begin{array}{l}\text { Automotive } \\
\text { Propulsion } 1\end{array}$ & 80 & 85 & 1.3 & 1.5 & 50 & 63.5 & 30 & 52.6 & 220 & 200 \\
\hline $\begin{array}{l}\text { Automotive } \\
\text { Propulsion } 2\end{array}$ & 68 & 73 & 1.4 & 1.6 & 40 & 48.2 & 50 & 52.7 & 220 & 200 \\
\hline $\begin{array}{l}\text { Automotive } \\
\text { Range } \\
\text { Extender }\end{array}$ & 75 & 80 & 1.5 & 2 & 80 & 69.5 & 80 & 69.5 & 150 & 150 \\
\hline $\begin{array}{c}\text { Automotive } \\
\text { APU }\end{array}$ & 75 & 80 & 1.5 & 2 & 80 & 69.5 & 80 & 69.5 & 150 & 150 \\
\hline $\begin{array}{l}\text { Stationary } \\
\text { CHP }\end{array}$ & 70 & 75 & 1.2 & 2 & 80 & 65 & 80 & 65 & Amb. & Amb. \\
\hline $\begin{array}{l}\text { Stationary } \\
\text { Backup } \\
\text { Power }\end{array}$ & 65 & 70 & 1.25 & 2 & 40 & 45.5 & 40 & 45.5 & 120 & Amb. \\
\hline $\begin{array}{l}\text { Portable } \mathrm{H}_{2-} \\
\text { PEMFC }\end{array}$ & 50 & 55 & 1.2 & 2 & 50 & 36.5 & Amb. & Amb. & 150 & Amb. \\
\hline $\begin{array}{c}\text { Portable } \\
\text { DMFC }\end{array}$ & 70 & Amb. & 5 & 2.5 & - & - & Amb. & Amb. & Amb. & Amb. \\
\hline
\end{tabular}

In general, all benchmark tests should be realized using pre-conditioned stacks. The break-in procedure for pristine stacks is typically specified by the stack manufacturer and has to be realized first. Afterwards, the stack should be operated for at least one hour at nominal load using the same application specific TOCs as used for the following benchmark test. Following the definitions for control sensor positioning and for control strategies summarized in this paper, as well as using the TOCs presented in Table 2, can then enable the reliable comparison of test results, not only in the scientific literature but also in the industry for stack benchmarking, even when the operating conditions in a target system should slightly differ from the suggested TOCs. 
An example of the impact of the TOCs on the test results is given in Figure 7. The test profile is shown in Figure 7a. The TOCs for automotive propulsion 2, stationary CHP, and portable $\mathrm{H}_{2}$-PEMFC were applied to the examined stack and the stack performance at $0.75 \mathrm{~A} \mathrm{~cm}^{-2}$ was determined. After applying the individual TOCs, the stack was conditioned for 30 minutes using the nominal conditions specified by the stack manufacturer.

The test results for the different TOCs are presented in Figure 7b. Two types of error bars were used in this result presentation. The black error bars represent the minimum/maximum deviation (see section 4.3) and the grey error bars represent the standard deviation of the average cell voltage over the analysis time. The stack performance using the TOCs for the stationary and the portable applications was quite similar, represented by an average cell voltage of $0.63 \mathrm{~V}$. The TOCs for the automotive application resulted in a significantly higher performance and an average cell voltage of $0.69 \mathrm{~V}$, mainly caused by the increased reactants pressures.
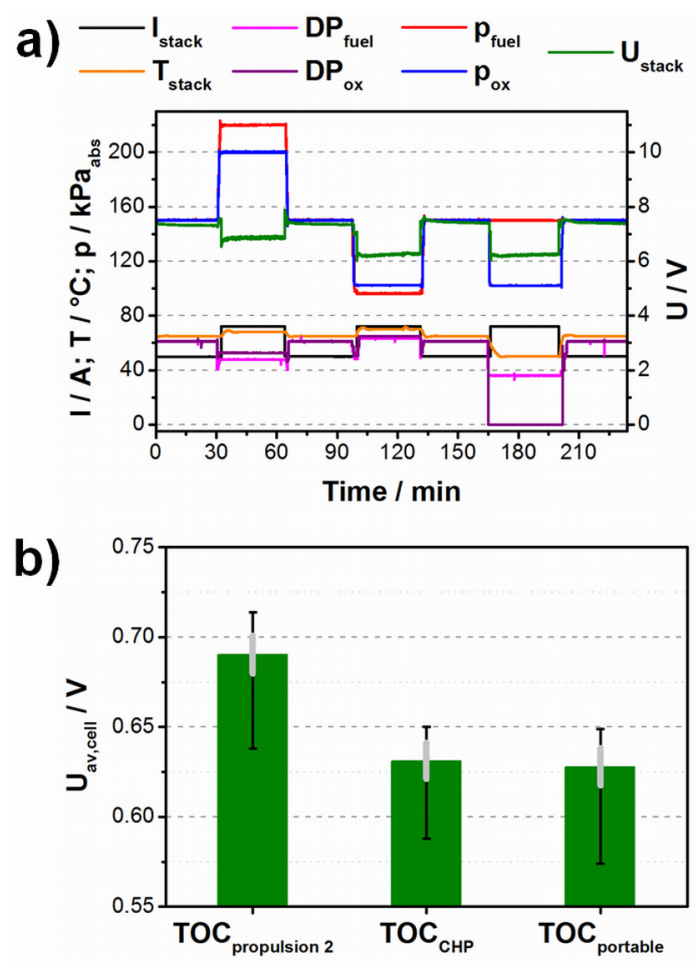

Fig. 7. Test profile (a) and test results (b) for the sensitivity of a stack to the TOCs summarized in Table 2.

\section{Reliable Stack Characterization by Polarization Curve}

The most common tool for PEMFC characterization regarding the impact of load levels on the stack performance is the polarization curve, but also the comparison of different polarization 
curves can be challenging. The results can significantly differ, even if the TOCs are the same. This can be caused by the choice of the test points and the variation of their dwell time. Furthermore, it is not always clearly indicated if the polarization curve was measured using an ascending or descending electrical load level variation. Both parts of the polarization curve significantly differ due to the presence or absence of catalyst surface species and the humidification level of the membrane. This hysteresis effect in the polarization curve cannot be avoided, no matter how much the dwell time is prolonged at each test points.

A concept was developed in the Stack-Test project to increase the comparability of polarization curves and minimize the impact of load set points and dwell times on the test results. This concept uses the calculation of "steady-state" polarization curves and is demonstrated in Figure 8. Both parts of the polarization curve, the descending and the ascending parts, were measured as shown by the test profile in Figure $8 \mathrm{a}$. The test procedure was started at the highest electrical load level defined before the test and the stack current was stepwise reduced to $0 \mathrm{~A}(\mathrm{OCV})$ to determine the descending polarization curve. Afterwards, the current was increased back to the highest load using the same current set points to determine the ascending polarization curve. The procedure was started with the descending polarization curve to assure a well-conditioned stack prior to the start of the measurement. This was provided because of well-defined conditions at high load corresponding to the predefined, well-adjusted stoichiometric ratios and humidity of the reactants. In contrast, the stack typically operates under excessively high stoichiometric ratios at low load because of a minimum reactant flow specified by the stack manufacturer. The operation of the stack under such conditions results in a partial stack dry-out because the excessive reactant flow removes too much of the reaction product water from the stack. As a consequence, the stack operation at low electric loads before the actual start of the procedure could affect the humidity state of the stack and the performance level of the first test points. This could result in noncomparable results of these test points.

The "steady-state" polarization curve was determined calculating the mean value of the average cell voltages from both parts of the polarization curve measurement for each load test point (see Figure $8 b$ ). This resulting curve represents a possibility to exclude the occurring 20 $\mathrm{mV}$ hysteresis effect and to compare the performance of different PEMFC stacks in benchmark tests without the influence of the preceding load levels and with a minor impact of set points and dwell times on the polarization curve results. A minimum dwell time of 5 minutes is recommended to assure data accuracy. 

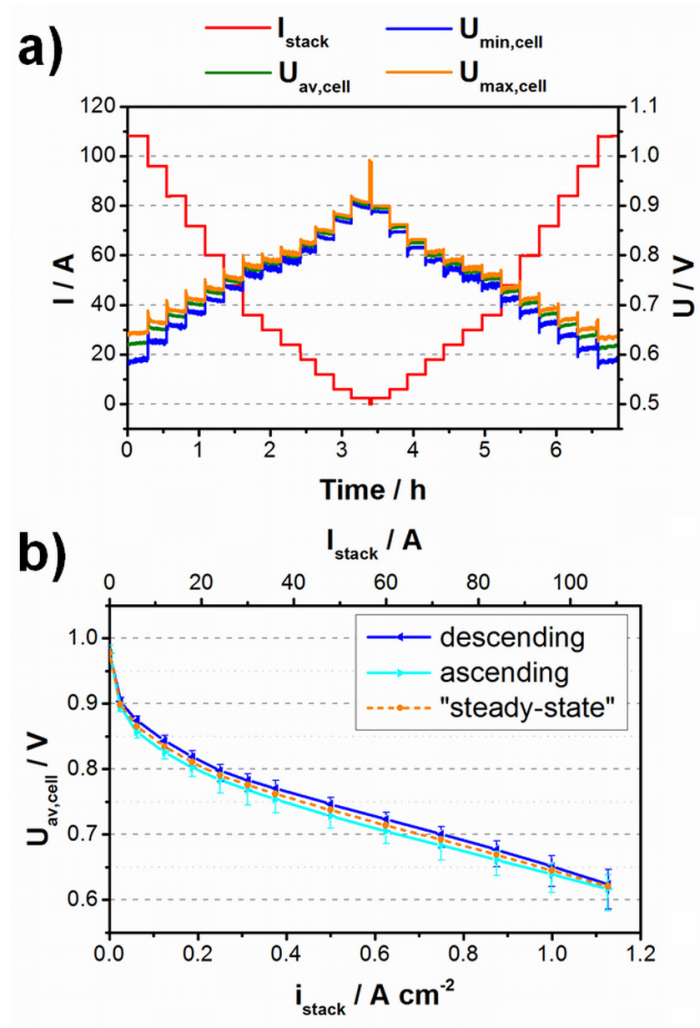

Fig. 8. PEMFC stack performance characterization by polarization curve measurements including the test profile (a) and the concept of "steady-state" polarization curves (b). TOCs: $\mathrm{T}_{\text {stack }}=85^{\circ} \mathrm{C} ; \lambda_{\text {fuel }}=1.2 ; \lambda_{\text {ox }}=2.0 ; \mathrm{DP}_{\text {fuel }}=$ $\mathrm{DP}_{\mathrm{ox}}=68.0^{\circ} \mathrm{C} ; \mathrm{p}_{\text {fuel }}=\mathrm{p}_{\text {ox }}=200 \mathrm{kPa}$ abs

\section{Conclusion}

This work is focused on the identification of critical parameters for PEMFC stack performance characterization and on the development of reliable benchmark methodologies to achieve comparable test results using different test equipment. Due to different possibilities for the positioning of the control sensors, their positions were clearly defined for all test operating parameters considering different aspects of stack safety, parameter stability, test duration, and comparability to an actual fuel cell system. The same aspects were considered for the definition of the control strategies for sensitivity benchmark tests using variable parameter set points. The results of sensitivity tests significantly differ when the tests are realized in different directions, from low to high values or vice versa. A summary of the control sensor positions and of the recommended directions for parameter changes are given in Table 1. These definitions ensure result comparability as well as stable test conditions and represent a control strategy for reliable stack benchmarking. E.g., the stack temperature fluctuation was minimized to about $1{ }^{\circ} \mathrm{C}$. The experiments have furthermore demonstrated 
that the reactants pressures can differ up to $12 \mathrm{kPa}$ for different positions of the control sensor. This critical parameter can result in an average cell voltage deviation of $21 \mathrm{mV}$ if the sensor position is not clearly defined.

A summary of recommended TOCs for comparable benchmark tests with respect to different applications is also given in this work. The different TOCs focused on automotive (propulsion, range extender, and APU), stationary (CHP and backup power), and portable applications $\left(\mathrm{H}_{2}\right.$-PEMFC and DMFC). The different conditions were harmonized after discussions with several companies and research institutions and are based on the state-of-the-art PEMFC technologies. The examined stack demonstrated comparable average cell voltage of $0.63 \mathrm{~V}$ for stationary and portable conditions. For automotive conditions, the voltage increased to $0.69 \mathrm{~V}$, mainly caused by higher reactants pressures.

Finally, a concept for the comparison of polarization curves was introduced in the present paper. The use of the "steady-state" polarization curve, calculated as mean values of the average cell voltages from the descending- and the ascending-load parts of the polarization curve measurement, is recommended. As a consequence, the occurring $20 \mathrm{mV}$ hysteresis effect between the ascending and descending polarization curve can be corrected and the concept enables comparison of the stack performance in benchmark tests without the influence of the preceding load levels on the following load levels and with a minor impact of the current set points and the test step dwell times on the polarization curve results.

The definitions of control sensor positioning and parameter variations summarized in this paper, together with the use of the suggested TOCs for different applications, enable reliable comparison of test results, not only in the scientific literature, but also in the industry. This presented control strategy for stack benchmarking was developed in the EU-funded project Stack-Test with the focus on PEMFC stack reference test procedures for industry. This project has prepared a variety of test procedures for all aspects of stack testing covering not only the presented characterization of stack performance, but also methodologies for reliable tests regarding stack durability and stack safety. All the prepared procedures are available as open source documents and can be obtained at the Stack-Test website [18]. 


\section{Acknowledgements}

The research leading to the presented results has received funding from the European Union Seventh Framework Programme (FP7/2007-2013) for the Fuel Cells and Hydrogen Joint Technology Initiative under grant $\mathrm{n}^{\circ} 303445$ (Stack-Test: Development of PEM fuel cell stack reference test procedures for industry). The Stack-Test project consortium is gratefully acknowledged for all discussions and testing activities to create test methodologies and test procedures for reliable and comparable PEMFC stack characterization. Furthermore, Siegfried Graf, Ioannis Komninakis, and Stefan Anderle are gratefully acknowledged for the preparation of the test station used in this work.

\section{References:}

[1] A. Kirubakaran, S. Jain, R.K. Nema, A review on fuel cell technologies and power electronic interface, Renew. Sustain. Energy Rev. 13 (2009) 2430-2440.

[2] B.D. James, J.M. Moton, W.G. Colella, Mass Production Cost Estimation of Direct H2 PEM Fuel Cell Systems for Transportation Applications: 2013 Update, Strategic Analysis Inc., 2014. http://energy.gov/sites/prod/files/2014/11/f19/fcto_sa_2013_pemfc_transportation_cost _analysis.pdf.

[3] W. Bernhart, S. Riederle, M. Yoon, Fuel cells - A realistic alternative for zero emission?, Roland Berger Strategy Consultants, 2013. http://www.rolandberger.com/media/pdf/Roland_Berger_Fuel_cells_20140113.pdf.

[4] A. de Frank Bruijn, G.M. Janssen, PEM Fuel Cell Materials: Costs, Performance and Durability, in: K.-D. Kreuer (Ed.), Fuel Cells SE - 9, Springer New York, 2013: pp. 249-303.

[5] Y. Wang, K.S. Chen, J. Mishler, S.C. Cho, X.C. Adroher, A review of polymer electrolyte membrane fuel cells: Technology, applications, and needs on fundamental research, Appl. Energy. 88 (2011) 981-1007.

[6] X. Li, I. Sabir, Review of bipolar plates in PEM fuel cells : Flow-field designs, Int. J. Hydrogen Energy. 30 (2005) 359-371.

[7] Z. Liu, L. Ma, J. Zhang, K. Hongsirikarn, J.G. Goodwin, Pt Alloy Electrocatalysts for Proton Exchange Membrane Fuel Cells: A Review, Catal. Rev. Sci. Eng. 55 (2013) $255-288$.

[8] G. Squadrito, O. Barbera, G. Giacoppo, F. Urbani, E. Passalacqua, Polymer electrolyte fuel cell stack research and development, Int. J. Hydrogen Energy. 33 (2008) 19411946. 
[9] G. Squadrito, G. Giacoppo, O. Barbera, F. Urbani, E. Passalacqua, L. Borello, et al., Design and development of a $7 \mathrm{~kW}$ polymer electrolyte membrane fuel cell stack for UPS application, Int. J. Hydrogen Energy. 35 (2010) 9983-9989.

[10] A.P. Manso, F.F. Marzo, J. Barranco, X. Garikano, M.G. Mujika, Influence of geometric parameters of the flow fields on the performance of a PEM fuel cell. A review, Int. J. Hydrogen Energy. 37 (2012) 15256-15287.

[11] International Electrotechnical Commission, IEC/TS 62282-7-1, FUEL CELL TECHNOLOGIES - Part 7-1: Single cell and stack test methods - Single cell performance tests for polymer electrolyte fuel cells (PEFC), 2010.

[12] U.S. DRIVE Fuel Cell Tech Team, Cell Component Accelerated Stress Test and Polarization Curve Protocols for PEM Fuel Cells, Appendix A, 2013.

[13] U.S. Department of Energy, DoE Cell Component Accelerated Stress Test Protocols for PEM Fuel Cells, 2007.

[14] FCTESTNET, Stationary Fuel Cell Systems Test Programs and Test Modules, 2006.

[15] FCTESQA, PEFC power stack performance testing procedure - Measuring voltage, power and efficiency as function of pressure for a water-cooled PEFC stack, Test Module PEFC ST 5-1, 2010.

[16] Japanese Industrial Standard, JIS C 8832 : 2008 (E), Performance test for stationary polymer electrolyte fuel cell stacks, 2008.

[17] Society for Automobile Engineers Fuel Cell Standards Committee, SAE J2617, Recommended Practice for Testing Performance of PEM Fuel Cell Stack Sub-system for Automotive Applications, 2011.

[18] Website of Stack-Test project, (2015). http://stacktest.zsw-bw.de/media-centre.html.

[19] P. Corbo, F.E. Corcione, F. Migliardini, O. Veneri, Energy management in fuel cell power trains, Energy Convers. Manag. 47 (2006) 3255-3271.

[20] S. Sun, H. Yu, J. Hou, Z. Shao, B. Yi, P. Ming, et al., Catalytic hydrogen/oxygen reaction assisted the proton exchange membrane fuel cell (PEMFC) startup at subzero temperature, J. Power Sources. 177 (2008) 137-141.

[21] P. Piela, J. Mitzel, Polymer electrolyte membrane fuel cell efficiency at the stack level, J. Power Sources. 292 (2015) 95-103.

[22] G. Tsotridis, A. Pilenga, G. De Marco, T. Malkow, EU Harmonised Test Protocols for PEMFC MEA Testing in Single Cell Configuration for Automotive Applications, doi: 10.2790/54653, ISBN: 978-92-79-54132-2, 2015.

[23] A. Martin, L. Jörissen, AutoStack-CORE - Industry Led European Consortium to Develop Next Generation Automotive Stack Hardware, ECS Trans. 69 (2015) 957-961. 
[24] J. Chen, B. Zhou, Diagnosis of PEM fuel cell stack dynamic behaviors, J. Power Sources. 177 (2008) 83-95.

[25] D. Candusso, F. Harel, A. De Bernardinis, X. François, M.C. Péra, D. Hissel, et al., Characterisation and modelling of a $5 \mathrm{~kW}$ PEMFC for transportation applications, Int. J. Hydrogen Energy. 31 (2006) 1019-1030.

[26] E. Calo, A. Giannini, G. Monteleone, Small stationary reformers for H2 production from hydrocarbons 5, Int. J. Hydrogen Energy. 35 (2010) 9828-9835.

[27] E. Varkaraki, N. Lymberopoulos, A. Zachariou, Hydrogen based emergency back-up system for telecommunication applications, J. Power Sources. 118 (2003) 14-22.

[28] H. Chang, C. Chou, Y. Chen, T. Hou, B. Weng, The design and cost analysis of a portable PEMFC UPS system, Int. J. Hydrogen Energy. 32 (2007) 316-322.

[29] J.P. Meyers, J. Newman, Simulation of the Direct Methanol Fuel Cell - II. Modeling and Data Analysis of Transport and Kinetic Phenomena, J. Electrochem. Soc. 6 (2002) A718-A728. 